\title{
Best Practices In Operations Executive Information Systems Software Development And Implementation
}

\author{
Tom Bramorski, (E-mail: bramorst@uww.edu), University of Wisconsin, Whitewater
}

\begin{abstract}
In this paper we identify best industry practices and current trends in the development and management of software products. We discuss the strategic importance of developing appropriate operational capabilities that are prerequisites for achieving marketing success. We illustrate these concepts with examples from software companies to highlight how they achieved the desired balance between market demands and operational resources. Finally, we highlight the benefits these companies had derived from such an alignment.
\end{abstract}

\section{INTRODUCTION}

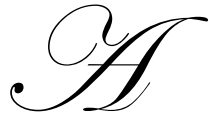

few characteristics of today's competitive Executive Information Systems (EIS) software markets are steadily increasing importance of product development speed, high quality and reliability and after-sale implementation and support. These requirements create operational challenges for businesses that include product development $\&$ testing, marketing $\&$ sales, software implementation $\&$ training, and technical support. In order to achieve high productivity software developers come under pressure to develop and implement a software product fast and at low cost. On the other hand, customers demand high quality, high speed, customized on-site product support and a high degree of product customization. Market demands must be appropriately reconciled with operational capacities and capabilities at the strategy level.

Consider an example of customer order processing. Typically, when a customer places an order, that order begins a route throughout various functional divisions of a company, its supply chain and ultimately its distribution units. When the computer systems of these separate organizational entities do not have an integrated IT platform, the order has to be keyed-in multiple times into different departments' computer systems. This causes delays, errors, lost orders, and loss of productivity. It adversely affects customer requirements for speed, high quality, and low cost. Frequently, no one in the company knows the order status, as it is "somewhere" in the system. Consequently, the accounts receivable department does not know when to bill the customer because they do not know whether the item has been shipped. Similar argument can be made for other organizational processes that operate more like disjoint entities rather than as an integral part of a larger system. Customers who are unable to precisely determine the status of their orders grow increasingly frustrated and may ultimately switch their purchases to the competitors. Clearly, a lack of accurate real-time information about poor order processing performance, which is important to customers in markets today, results in delayed of no corrective action at all on the part of senior sales executives. This forces the organization to react and rectify the damage after it occurred rather than prevent disasters from happening.

EIS provide senior level executives the ability to obtain accurate, timely and intimate insights into actual performance in a flexible fashion (as required by the user, by product, by plant, by market, by competitive priority, etc.) using the value based approach. These reports may vary in the level of aggregation they use and may be selected by the system end-user in an easy and intuitive way. 


\section{THE STRATEGIC FIT AND BENEFITS OF EIS}

It is important for companies to formally map their ways of doing business in order to allow them to determine whether they will fit within a standard ERP package options before the ERP software is selected for implementation. These decisions determine the information that the EIS system will be able to present to the endusers. Hence, the EIS can be successfully implemented only after the implementation of ERP has been successfully completed. The most common reason that companies abandon multimillion-dollar ERP projects is that they discover the software does not support one of their important business processes. At that point there are two things they can do: They can change the business process to accommodate the software, which will mean deep changes in longestablished ways of doing business. The alternative is to modify the software to fit the process, which will slow down the project, introduce dangerous bugs into the system and make upgrading the software to the ERP vendor's next release excruciatingly difficult because the customizations will need to be torn apart and rewritten to fit with the new version [2].

EIS attempts to integrate all departments and functions across a company onto a single computer system that can serve the particular needs of selected top-level executives utilizing the capabilities of an existing ERP system. A high degree of integration between organizational functions enabled by ERP systems, such as SAP or Business One, allows finance, manufacturing and other functions to use their own software. The ERP software with custom applications is linked together so that accounts payable can verify (by using inventory management software) that an order has been shipped so that they can bill the customer accordingly. The same information is available to senior level executives in real time at a strike of a key on their EIS terminal. Most vendors' ERP software is flexible enough that you can install some modules without buying the whole package. Many companies, for example, will just install an ERP finance or HR module and leave the rest of the functions for later. While this makes the implementation more flexible and spreads it over time, it also limits the features of the EIS system that is linked with ERP.

Many senior business managers believe that EIS and ERP systems are implemented for far more significant strategic reasons [1]. According to [2] a Meta Group study of 63 companies found that it took eight months after the new system was in (31 months total) to see any benefits. But the median annual savings from the new ERP system were $\$ 1.6$ million. Some of these benefits include:

1. Cross-functional business processes are brought to the forefront and allow information to be shared horizontally, between functions and business units; and vertically, from the front-line to the strategic levels,

2. Capability of real-time reporting of different complexity on different performance criteria across organizational units and functions is enhanced,

3. Operating costs are reduced,

4. Easy identification of waste (activities that do not add value,) such as excess inventories,

5. Focus on improving customer satisfaction (by improving late deliveries and customer service resources,)

6. ERP-enabled business processes and data are standardized and normalized,

7. Organizational boundaries dissolve - creating a business where departments are constantly "talking" to one another,

8. Independent business units are integrated - forming one business unit,

9. Jobs broaden and/or are redefined via expanded information access,

10. The availability of information fosters empowerment of employees,

11. There is system-wide accountability and visibility that helps to ensure people do things right the first time,

12. More accurate demand forecasts are generated.

While the potential benefits from deploying EIS in organizations are very significant, there are also significant risks that must be addressed for the implementation to be successful. For EIS implementations success is achieved when the system implementation allows executives appropriate views of information (flexibility), while maintaining data integrity (accuracy), in real-time (fast) and within budget (cost). Following are the major internal factors that determine whether or not EIS should be implemented in an organization [4]. 
1. If its supply chain includes global \& multiple distribution centers and plants, an EIS system is essential,

2. If its manufacturing is capital intensive and involves complex products and broad product lines, EIS will have a larger impact due to its ability to gain more insights in a timely fashion,

3. If the company has built up a fragmented set of legacy systems over the years may be sufficient reason to upgrade to an EIS package. Modern systems can do so much more, and there are great advantages to working from a common database integrating global suppliers.

An EIS system utilizes data available in the ERP system databases. Therefore, a well-conceived implementation of a business-wide ERP system must precede the development of an EIS system in a way consistent with business strategy. The EIS operational requirements critical to top-level executives include real-time response, flexibility and customization capabilities, simple and intuitive user interface, and extensive reporting capabilities. On the design side, EIS systems must provide quick response, accuracy, consistency of data and data formats across business units, organizational functions and product lines and flexible integration with an existing single businesswide ERP system.

Specific strategic benefits for companies to that implement integrated ERP/EIS solutions using process orientation include [2]:

1. Integration of financial information. As the top-level executive tries to assess the company's overall performance, he/she may find many different versions of true organizational performance. Finance has its own set of revenue numbers, sales has another version, and the different business units may each have their own version of how much they contributed to revenues. ERP creates a single version of the truth that cannot be questioned because everyone is using the same system. The EIS presents this single, integrated view to top-level executives.

2. Integration of customer order information. ERP systems increase transparency by allowing reliable order tracking from the time a customer service representative receives the order until the loading dock ships the merchandise and finance sends an invoice. By having this information in one software system, rather than scattered among many different systems that cannot communicate with one another, companies can keep track of orders more easily, and coordinate manufacturing, inventory and shipping among many different locations at the same time. The EIS allows the top-level executives to easily determine critical strategic performance measures for a specific customer, product or market, such as on-time shipments or conformance quality. In addition, the EIS system allows an executive to easily determine the key characteristics of a customer, such as quarterly sales volume.

3. Standardization and speeding up manufacturing processes. Businesses often have to deal with a myriad of legacy computer systems that are not integrated and operations processes that are different. This is particularly relevant for companies that produce a broad variety of products in geographically scattered environments. ERP systems incorporate standard methods for automating some of the steps of a manufacturing process. Standardizing those processes and using a single, integrated computer system can save time, increase productivity and reduce head count. The EIS system allows executive insights into organizational performance for different products and markets. Such insights use comprehensive data from businesses across the entire supply chain.

4. Reduction of inventory at all levels. ERP systems provide information that allows process flow of raw materials, WIP and finished goods to be smooth. It improves visibility of the order fulfillment process throughout the internal and external supply chain. That can lead to reduced inventories and help users better plan deliveries of products and services to customers, reducing the finished good inventory and improving on-time performance. The EIS system allows executive instantaneous insights into process details for any product in any business unit. Such insights use comprehensive data from businesses across the entire supply chain and are essential for timely identification of bottlenecks and sources of waste.

5. Standardization of $H R$ information. HR in organizations usually lacks a unified, simple method for determining performance-related measures, such as tracking employees' time and communicating with them about benefits and services. This is especially true in diversified global companies with multiple business units serving different customers in different markets. A similar argument may be made in determining training and educational needs and cafeteria benefits. In the race to fix these problems, companies often 
develop local HR applications that do not communicate with the environment. While most ERP packages are highly comprehensive, each industry has its unique measures and characteristics. Most ERP systems were designed to be used by large and medium size discrete manufacturing companies and are hard to customize for other industries, including process manufacturers, services, and education. Each of these industries has struggled with the different ERP vendors to modify core ERP programs to fit their needs. The EIS system allows executive instantaneous insights into HR information specific to a department, process or business unit. This allows for a quick calculation of productivity measures, demographic information, training needs, and trends in a way consistent with the firm's strategic objectives. Such internal insights are essential for determining sound HR strategies when combined with external HR intelligence information.

6. Intelligence gathering and analysis. EIS systems provide executives with timely intelligence information regarding the external business environment in which the organization operates for each product line and each geographic market. This aspect includes information about current and future trends as far as product/service design, features, cost, technology and materials, pricing, environmental issues, etc. In addition, the intelligence module contains information about the competition and their current and expected moves. Finally, the module has information about the current legislative situation and expected changes as they impact certain locations, products or technologies. This capability gives executives an ability to authorize appropriate changes to organizational processes, specifically including operations, in anticipation of changes in the competitive picture.

7. Risk assessment. EIS systems have a capability to quantify risk and perform business simulations under certain scenarios. This allows executives to select business scenarios that can generate the most benefit to the organization while minimizing its exposure to risk. The executive decisions, in turn, are more robust in that they represent a well thought-over balance between several conflicting organizational objectives.

\section{THE TIME FRAME OF ERP/EIS IMPLEMENTATION}

ERP and EIS systems tend to be highly customized to fit well to the specific needs of the entire business and the senior level executives of an organization. The actual development, implementation and fine-tuning time usually covers 3-5 years for a large organization. As the single system implementation progresses issues such the scope, the existing legacy and ERP platforms, the required degree of integration need to be addressed. To implement the ERP properly it is necessary for people in the organization to fundamentally change the way they do business and to adopt process orientation clearly identifying the areas where value gets added and where waste is generated. This is done by implementing value management, in which the contributions elements of the organization's internal and external chains make to support competitive priorities in market segments. After the implementation of a single ERP system has been completed and fine-tuned, the EIS implementation can begin. As in case of ERP systems, this step takes 2-3 years for a large organization because of a need for extensive customization of system capabilities and the need to integrate it with an existing ERP platform.

There are three commonly used ways of installing ERP and EIS [2].

1. The comprehensive change approach. This is the most ambitious and difficult of approaches to ERP implementation. At a predetermined time a company decommissions all their legacy systems at once and installs a single ERP system across all of its business units. Though this method dominated early ERP implementations, few companies attempt it anymore because it calls for the entire company to mobilize and change at once. Most of the ERP implementation horror stories from the late '90s warn us about companies that used this strategy. Getting everyone to cooperate and accept a new software system at the same time is a tremendous effort, largely because the new system will not have any advocates. No one within the company has any experience using it, so no one is sure whether it will work. Also, ERP inevitably involves compromises. Many departments have computer systems that have been honed to match the ways they work. In most cases, ERP offers neither the range of functionality nor the comfort of familiarity that a custom legacy system can offer. In many cases, the speed of the new system may suffer because it is serving the entire company rather than a single department. Since this mode of implementation is characteristic of breakthrough reengineering it requires a direct mandate and constant active support from the CEO. 
2. The step-by-step approach. This approach is appropriate for large or diverse companies that do not share many common processes across business units. This situation typically develops in cases when a company rapidly expands through mergers and acquisitions. Independent legacy ERP systems are typically installed in each business unit, while linking common processes, such as financial bookkeeping, across the enterprise. This has emerged as the most common way of implementing ERP in the current decade. In most cases, the business units each have their separate legacy ERP systems and databases. The systems link together only to share the information necessary for the corporation to get a performance big picture across all the business units (e.g. business unit or product revenues,) or for processes that don't vary much from business unit to business unit (e.g. HR benefits.) Usually, these implementations begin with a demonstration or pilot installation in a particularly open-minded and patient business unit where the core business of the corporation will not be disrupted if something goes wrong. Once the project team gets the system up and running and works out all the bugs, the team begins selling other units on ERP, using the first implementation as a kind of in-house customer reference. Usually this strategy takes a long time to implement and fine-tune.

3. The selective approach. Under this approach the ERP system dictates the process design. Usually, the implementation focus is on just a few key critical processes, such as those contained in an ERP system's financial module. The selective approach is generally successful in small or medium size companies expecting to grow into full-scale class I ERP system some time in the future. The goal here is to get ERP up and running quickly, with minimal cost and on schedule. Therefore, such applications usually deploy "canned" processes that are difficult to customize. Hence, the companies that select this mode must reengineer their processes in advance to fit the standard software requirements prior to the beginning of scheduled system implementation. Few companies that have implemented ERP this way can claim much payback from the new system. Most use it as an infrastructure to support more diligent installation efforts down the road. Yet many discover that a slammed-in ERP system may be only a little better than a legacy system because it doesn't force employees to change any of their old habits. In fact, doing the hard work of process reengineering after the system is in can be more challenging than if there had been no system at all because at that point few people in the company will have felt much benefit.

The benefits derived for EIS systems clearly depend on the choice of ERP implementation model. These benefits are maximized under a comprehensive change approach has been adopted. This reduces system maintenance expenditures and improves information quality.

\section{CONFIGURATION AND COSTS OF ERP SOFTWARE}

It has been established that it is important for a company to justify implementing ERP and EIS systems in strategic terms using a value-added approach. However, the ERP software packages are built from thousands of database tables, that IS programmers and end users must set to match their business processes. Each table has a decision "switch" that leads the software down one decision path or another. By presenting only one way for the company to do each task, a company's individual operating units and divisions are integrated under one system. But figuring out precisely how to set all the switches in the tables requires a deep understanding of the existing processes being used to operate the business. As the table settings are decided, these business processes must be reengineered to conform to the way the software defines these processes. Most ERP systems are not shipped as a shell system in which customers must carefully determine how all the detailed functional procedures should be set, making thousands of decisions that affect how their system behaves in line with their own business activities. Most ERP systems are preconfigured, allowing just hundreds rather than thousands of procedural settings to be made by the customer. While this makes implementation simpler, it also increases the amount of work involved in reengineering key organizational processes to make them conform to software requirements. This work must be completed prior to the beginning of ERP software implementation. This reduces the ability of the user to customize software features. Clearly, a standard ERP implementation may not appropriately meet the specific requirements of top-level executives who rely on the EIS system utilizing only standard ERP outputs.

Since ERP/EIS system development and implementation are projects of business-wide scope, they are very costly and time consuming. In addition to paying for the software and subsequent updates, organizations must pay for cover consulting services, process reengineering, integration testing and many other expenses. These are up-front 
costs that must be incurred before the benefits of ERP and EIS start to even manifest themselves. Underestimating the price of teaching users their new job processes can lead to a rude shock down the line, and so can failure to consider data warehouse integration requirements and the cost of extra software to duplicate the old report formats. A few oversights in the budgeting and planning stage can send ERP costs spiraling out of control faster than oversights in planning almost any other information system undertaking.

Meta Group recently did a study looking at the total cost of ownership (TCO) of ERP, including hardware, software, professional services and internal staff costs. The TCO numbers include getting the software installed and the two years afterward, which is when the real costs of maintaining, upgrading and optimizing the system for your business are felt. Among the 63 companies surveyed-including small, medium and large companies in a range of industries - the average TCO was $\$ 15$ million (the highest was $\$ 300$ million and lowest was $\$ 400,000$ ). While it's hard to draw a solid number from that kind of range of companies and ERP efforts, Meta came up with one statistic that proves that ERP is expensive no matter what kind of company is using it. The TCO for a "heads-down" user over that period was $\$ 53,320$. Experiences of organizations that successfully implemented ERP and EIS systems demonstrate that good ERP implementations pay for themselves is 3-4 years while EIS implementations typically require a 1.5-2 years payback period.

Although different companies will find different cost components in the budgeting process, those who have implemented ERP packages agree that certain costs are more commonly overlooked or underestimated than others. Armed with insights from across the business, ERP pros identify the following areas as most likely to result in budget overrun [2].

1. Training. Training is the near-unanimous choice of experienced ERP implementers as the most underestimated budget item. Training expenses are high because workers almost invariably have to learn a new set of processes, not just a new software interface. Worse, outside training companies may not be able to help you. They are focused on telling people how to use software, not on educating people about the particular ways you do business. Prepare to develop a curriculum yourself that identifies and explains the different business processes that will be affected by the ERP system. With ERP implementation across the business, finance people will be using the same software as warehouse people and they will both be entering information that affects the other. To do this accurately, they have to have a much broader understanding of how others in the company do their jobs than they did before ERP came along. Ultimately, it will be up to organization's IT and business people to provide that training. A common practical advice from ERP system implementers is to take whatever you have originally budgeted for ERP training and double or triple it up front to make the transition as smooth as possible. Consequently, it is advisable to start reengineering existing organizational processes and user training at all levels of the organization early, even before the system implementation had begun.

2. Integration and testing. Testing the links between ERP packages and other corporate software links that have to be built on a case-by-case basis is another often-underestimated cost. A typical company may have add-on applications from the major (e.g. e-commerce and supply chain) to the minor (sales tax computation and bar coding.) All require integration links to ERP. If add-ons can be purchased from the ERP system vendor that are pre-integrated, it is clearly a preferred choice. If the links have to be coded in the house, they will take a long time and cost a lot of money. As with training, testing ERP integration has to be done from a processoriented perspective. Practitioners recommend that instead of plugging in dummy data and moving it from one application to the next, run a real purchase order through the system, from order entry through procurement, manufacturing, shipping and receipt of payment preferably with the participation of the employees who will eventually do those jobs. This will provide valuable hands-on training capabilities and create an opportunity to verify that the system processes data correctly.

3. Customization. Add-ons are only the beginning of the integration costs of ERP. Much more costly, and something to be avoided if at all possible, is actual customization of the core ERP software itself. This happens when the ERP software cannot handle one of your business processes and a decision is made to modify the software rather than to change the process. These customizations can affect every module of the ERP system because they are all so tightly linked together. Upgrading the ERP package at some future time will be extremely cumbersome as the add-ons will typically not be compatible with the new version of the 
ERP software. Hence, these customizations will have to be redone in the new version, which will reduce system reliability and possibly adversely affect data integrity. Since the ERP software vendor will not support add-ons and customizations, the implementation and debugging will have to be done entirely in-house.

4. Data conversion. It costs money to move corporate information, such as customer and supplier records, product design data and the like, from old systems to new ERP homes. Although few CIO's will admit it, most data in most legacy systems is of little use. Companies often deny their data is dirty until they actually have to move it to the new client/server setups that popular ERP packages require. Consequently, those companies are more likely to underestimate the cost of the move. But even clean data may demand some overhaul to match process modifications necessitated by the ERP implementation. The problem is further exacerbated when the organization has to deal with several legacy systems and custom applications that do not talk to one another.

5. Data analysis. Often, the data from the ERP system must be combined with data from external systems for analysis purposes. Users with heavy analysis needs should include the cost of a data warehouse in the ERP budget and they should expect to do quite a bit of work to make it run smoothly. Users have a dilemma. On the one hand, refreshing all the ERP data every day in a big corporate data warehouse is difficult. On the other hand, ERP systems do a poor job of indicating which information has changed from day to day, making selective warehouse updates tough. One expensive solution is custom programming. The upshot is that the wise will check all their data analysis needs before signing off on the budget.

6. Consultation services. When users fail to plan for disengagement, consulting fees usually increase dramatically. To avoid this, companies should identify objectives for which its consulting partners must aim when training internal staff. Such agreements should include metrics in the consultants' contract. For example, a specific percentage of the user company's staff should be able to pass a project management leadership test.

7. Replacing the best and brightest. It is accepted wisdom that ERP success depends on staffing the project with the best and brightest from the business and IS divisions. The software is too complex and the business changes too dramatic to trust the project to just anyone. The bad news is a company must be prepared to replace many of those people when the project is over. Though the ERP market is not as hot as it once was, consultancies and other companies that have lost their best people will be hounding yours with higher salaries and bonus offers than you can afford or you are allowed to offer. Hence, it is important to work with HR early to develop a retention bonus program and create new salary strata for ERP veterans. If you let them go, you will wind up hiring them or someone like them back as consultants for twice what you paid them in salaries.

8. Continuous implementation teams. Most companies intend to treat their ERP implementation as they would any other software project. Once the software is installed, they figure the team will be scuttled and everyone will go back to his or her day job. Since the system implementers are too valuable and have worked intimately with ERP, they usually know more about the sales process than the salespeople and more about the manufacturing process than the manufacturing people. Companies cannot afford to send their project people back into the business because there is a lot of work to do after the ERP software has been installed. Just writing reports to pull information out of the new ERP system will keep the project team busy for a year at least. It is in analysis and insight that companies make their money back on an ERP and EIS implementation. Unfortunately, few IS departments plan for the frenzy of post-ERP installation activity, and fewer still build it into their budgets when they start their ERP projects. Many are forced to beg for more money and staff immediately after the go-live date, long before the ERP project has demonstrated any benefit. Therefore, in order to realize strategic benefits from system implementation, top executives must support the continuous improvement effort in this area.

9. Realization of ROI. One of the most misleading legacies of traditional software project management is that the company expects to gain value from the application as soon as it is installed, while the project team expects a break and maybe a pat on the back. Neither expectation applies to ERP or EIS. Most of the systems do not reveal their value until after companies have had them running for some time and can concentrate on making improvements in the business processes that are affected by the system. And the project team is not going to be rewarded until their efforts pay off.

10. Post-implementation depression. ERP and EIS systems often wreak cause havoc in the companies that install them. In a recent Deloitte Consulting survey of 64 Fortune 500 companies, one in four admitted that they suffered a drop in performance when their ERP system went live. The true percentage is undoubtedly much higher. The most common reason for the performance problems is that everything looks and works differently 
from the way it did before. When people cannot do their jobs in the familiar way and have not yet mastered the new way, they panic. This adversely affects overall business performance.

\section{THE REASONS OF FAILURES}

At its simplest level, ERP is a set of best practices for performing different duties in your company, including finance, manufacturing and the warehouse. To realize full software potential, employees in the company must adopt the work methods outlined in the software. If the people in the different departments that will use ERP do not agree that the work methods embedded in the software are better than the ones they currently use, they will resist using the software or will want IT to change the software to match the ways they currently do things. This is where ERP projects break down. Political fights break out over how or whether the software will be installed. IT gets bogged down in long, expensive customization efforts to modify the ERP software to fit with existing process needs. Customizations make the software more unstable and harder to maintain when it finally does come to life. The horror stories you hear in the press about ERP can usually be traced to the changes the company made in the core ERP software to fit its own work methods. Because ERP covers so much of what a business does, a failure in the software can bring a company to a halt [3].

A major reason for system development and implementation problems is people resistance to change. But IT can fix the bugs pretty quickly in most cases, and besides, few big companies can avoid customizing ERP in some fashion. As noted earlier, every business is different and is bound to have unique work methods that a vendor cannot account for when developing its software. The mistake companies make is assuming that changing people's habits will be easier than customizing the software. In reality, the opposite is true. Getting people inside your company to use the software to improve the ways they do their jobs is by far the harder challenge. If your company is resistant to change, then your ERP project is more likely to fail. The ERP and EIS systems are process-oriented and necessitate that employees change the way they do their jobs. Hence, the benefit of the system will best be realized when EIS is used in connection with ERP to improve the ways employees process orders, manufacture goods, etc.

While EIS benefits are sought after in today's productivity and efficiency oriented corporate climate, they do come at a price, and sometimes it is more than what the investors were expecting to take on. In fact, the current consensus is that many companies have failed to reap the significant benefits that a massive investment in the system. Below we identify some reasons are that ERP and EIS projects have failed to bring the expected results [3].

1. They represented very large investments for the organizations concerned, much larger than originally anticipated,

2. They have been very painful to implement and left the organization drained and resistant to launching further projects. This is particularly important for network and matrix organizations that involve extensive collaboration throughout global supply and distribution chains,

3. They have not taken into consideration the all the hidden costs in the form of the internal resources deployed and the consequent loss of focus on the business associated with an implementation, and

4. They delivered limited business benefits over and above installation of new base systems infrastructure.

There are three elements that must be managed in order for an organization to realize more benefit from an EIS implementation [5].

1. The development of an exploitation strategy. This is primarily concerned with identifying projects that utilize the base infrastructure and deliver the biggest benefits. The challenge is finding people who understand the business and its processes, understand the technology and can identify quickly where a business can change and improve performance. The types of projects that are emerging in developing these exploitation strategies include:

a. Reengineering around existing installed modules,

b. Installation of new modules, 
c. Use of 'new dimension products' from suppliers, or complementary software from niche suppliers, to get more from customer relationship management, supply-chain management, and information management, and

d. Internet applications linked to EIS (such as ERP) to open up new sales channels or fundamentally change the nature of the business,

The portfolio needs to be shaped into a program those factors in the need of upgrades and the availability of key resources within the organization.

2. The development of benefit-focused (value-creation) implementation plans. Developing plans that respond to the benefit opportunities available will demand the involvement of the business in identifying the potential changes that could be made and developing business requirements that will underpin those changes. The resulting plan will be more focused on activities that ensure that the business stays involved and to ensure that the changes are made.

The most critical component of this element is the development of detailed business cases. In the past it has been easy to get projects through the investment net on relatively flimsy business cases. This should not be allowed to continue and involving the right users in the development of the cases builds a sense of ownership in the outcomes.

3. The establishment of recognizable benefit delivery processes. A formal process is required that is initiated as part of the development of the business cases and ends well after the systems and processes go live.

At an early stage, the benefits need to be well articulated and evaluated. Accountability for their delivery needs to be clearly allocated and communicated. This accountability often needs to be shared to reflect dependencies on other functions or processes and these dependencies need to be clear so that people do not wriggle out of their commitments at a later date. Sustaining mechanisms need to be incorporated, e.g. the inclusion of the expected results in budgets or performance measures. Having these results included in a manager's compensation arrangements is a particularly compelling technique.

Around the build-up to going live it is easy to lose sight of the original purpose of the project: it's benefit. Providing the support mechanisms around and after going live are therefore critical to retain focus on overcoming the inevitable dip in performance after going live, ramping up to a stabilized performance level as fast as possible and then going forward to delivery of the expected benefit. Installing the sustaining performance monitoring mechanisms to encourage continuous improvement also continuous improvement also contributes to building a culture of benefit delivery. This helps enormously, as there will always be the next project in the exploitation strategy to manage" [5].

\section{CONCLUSIONS}

In this paper we established the importance of justifying the implementation of ERP and EIS systems in strategic terms. We noted that the system implementation must improve organizational performance on selected key performance measures important to the customers, such as speed and quality. We established that the EIS and ERP systems must be closely knit in order to meet specific executive requirements and discussed factors that are critical to achieving successful implementation of EIS systems. Finally, we discussed key system implementation drivers and presented selected system implementation experiences.

\section{REFERENCES}

1. $\quad$ Benoit, G., "The Winds of Change," CMA Management, 2001, 75(8), 34.

2. $\quad$ Koch, C. "ERP System Implementation," Senior Editor APICS Newsletter, Fall 2003.

3. Romeo, J., "Less Pain, More Gain in ERP Rollouts," Network Computing, 1997, 12(19), 49.

4. $\quad$ Rooney, C., "Is an ERP System Right for You?" Adhesives Age, 2000, 43(9), 30.

5. Smith, M., "Realizing the Benefits from Investment in ERP," Management Accounting: Magazine for Chartered Management, 1999, 77(10), 34. 


\section{NOTES}

